\title{
CDISC SDTM Tumor or Lesion Properties Test Code Terminology
}

National Cancer Institute

\section{Source}

National Cancer Institute. CDISC SDTM Tumor or Lesion Properties Test Code

Terminology. NCI Thesaurus. Code C96779.

Terminology associated with the oncology tumor properties test code codelist of the Clinical Data Interchange Standards Consortium (CDISC) Study Data Tabulation Model (SDTM). 